\title{
NUMERICAL RESEARCH FOR THE START CONTROL AND FINAL OBSERVATION PROBLEM IN MODEL OF THE DISTRIBUTION OF POTENTIALS IN A CRYSTALLINE SEMICONDUCTOR
}

\author{
K. V. Vasiuchkova, South Ural State University, Chelyabinsk, Russian Federation, \\ vasiuchkovakv@susu.ru
}

\begin{abstract}
The article considers the numerical research of the mathematical model of control of potential distribution in a crystalline semiconductor. This model based on the problem of start control and final observation by weak generalized solutions of mathematical model of potential distribution in a crystalline semiconductor. This model belongs to the class of mathematical models based on semilinear Sobolev type equations with $p$-coercive and $s$-monotonous operators. We have shown the existence and uniqueness of a weak generalized solution of the investigated model with the initial condition of Showalter-Sidorov and found sufficient conditions the existence of a solution to the problem of start control and final observation. We construct the algorithm of the numerical method to solve the problem of start control and final observation for the model of control potential distribution in a crystalline semiconductor, based on method of decomposition and method of Galerkin. Computational experiments are given.

Keywords: Sobolev type equation; problem of start control and final observation; mathematical modelling; the Galerkin method; decomposition method.
\end{abstract}

\section{Introduction}

At the present stage of development, application, industry of electronic computers leave to important studying physics of semiconductor. Since full-scale experiments is difficult, so mathematical modelling [1-4] is an important role in the study of these processes. We can control many processes occurring in semiconductor-type substances, by changing the parameters of environmental (for example, the magnitude of the magnetic field) and the internal environment (for example, temperature, chemical composition semiconductor). The study of the rational state of the system and finding an optimal law of control for these systems are important practical problem in field of numerical modelling processes [5-8]. For this, we are developing various mathematical, algorithmic and software. Purpose of this article is a research of the mathematical model of distribution control potentials in a crystalline semiconductor, based on the problem starting control and final observation

$$
J(x(T), u)=\vartheta\left\|x(T)-x_{f}\right\|_{W_{4}^{1}(\Omega)}^{4}+(1-\vartheta)\|u\|_{W_{4}^{1}(\Omega)}^{4} \rightarrow \inf , \quad \vartheta \in(0,1)
$$

by weak generalized solutions of the mathematical model of the distribution of potential in a crystalline semiconductor, based on the Sobolev type equation

$$
(\lambda-\Delta) x_{t}-a_{1} \Delta x-a_{2} \operatorname{div}\left(|\nabla x|^{2} \nabla x\right)=y
$$

with the initial the Showalter-Sidorov condition

$$
(\lambda-\Delta)(x(s, 0)-u(s))=0, \quad s \in \Omega
$$


with the Dirichlet condition

$$
x(s, t)=0, \quad(s, t) \in \partial \Omega \times \mathbb{R}_{+} .
$$

In the considered problem of start control and final observation (1) is: $J(x(T), u)$ is a specially constructed target functional; $u \in \mathfrak{U}_{a d}, \mathfrak{U}_{a d}$ is a closed and convex set in the space of controls $\mathfrak{U}$, function $x_{f}=x_{f}(s)$ is the required state which, the system has to achieve with a minimum initial exposure to the passage of time $t=T$. In equation (2) the function $x=x(s, t)$ describes the potential electric field, a given function $y(s, t)$ characterizes the external influence, for example, the influence of an external magnetic field, and the parameters $\lambda \in \mathbb{R}, a_{1} a_{2} \in \mathbb{R}, \Omega \subset \mathbb{R}^{n}$ is a bounded domain with boundary $\partial \Omega$ класса $C^{\infty}$.

Note that equation (2) is a multidimensional generalization of model onedimensional equations describing waves of Rossby. This is traveling waves generated in the atmospheres of planets and in the oceans in moderate widths mouths. Since these equations are model, they are also suitable to describe the processes occurring in semiconductors. Mathematical model of process distribution potential in a crystalline semiconductor are first presented in [1]. And in the case $a_{1}=1, a_{2}=1$ it was shown that in the presence of current sources of free charges or negativity of differential conductivity there is a breakdown of semiconductors (because potential energy of a system exceeds kinetic). In [9] the generalized equation of the form

$$
(\lambda-\Delta) x_{t}-a_{1} \Delta x-a_{2} \operatorname{div}\left(|\nabla x|^{2} \nabla x\right)+a_{3}|x|^{p-2} x=f, \quad p \geq 2 .
$$

is investigated. Here $\lambda \in \mathbb{R}, a_{1} a_{2} \in \mathbb{R}, a_{3} \in\{0\} \cup \mathbb{R}_{+}$. This article [9] also shows the existence of a quasi-stationary trajectory based on the phase space method. This approach is one of the main methods for studying equations of this type. This method was first proposed in the work G.A. Sviridyuk. Later, this approach to the study of semilinear Sobolev type equations was used in studies of various models of mathematical physics $[10,11]$. In this article we will investigate the equation (2), which belongs to the class of semilinear Sobolev type equations with $p$-coercive and $s$-monotonic operators. Note that the coercive operator is strongly $p$-coercive, and the $s$-monotonic operator is strictly monotonous.

The problem of start control and final observation simulates the situation when the moment of result observation is separated in time from the start influence, i.e. control. The problem $(1)--(4)$ describes process to find the initial distribution potential $u(s)$ in a semicrystalline semiconductor, at which under the action of a direct electric current $y(s, t)$ after a time $t=T$ they will take the required distribution $x(s, T)$. In the case of a nonlinear equation, searching start control is difficult. One approach to solving this problem is the method of decomposition $[12,13]$. This method allows to linearize the initial equation and to transfer the phenomenon of nonlinearity to the functional. Therefore, the numerical scheme to find the approximate solution to the problem of start control and final observation is simplified. In [8] proved the existence and uniqueness of the start control and final observation for parabolic equations. In [5] sufficient conditions for the solvability problem of the start control and final observation for one abstract quasilinear of Sobolev type equation in a weak generalized case were obtained, and the solvability problem of start control and final observation for the model of Barenblatt-Guilman is proved. Analytical 
and numerical research problem of start control and final observation for one class Sobolev type equations with the Showalter-Sidorov condition presents in [7].

The article is organized as follows. The first paragraph presents a reduction of the problem (1) - - (4) to the abstract problem, based on a semilinear Sobolev type equation. To this end, we construct the function spaces and show the basic properties of the operators, establish an existence of the weak generalized solution to the problem (2) - - (4). Also, we study the problem of start control and final observation (1) - - (4) and present the sufficient conditions for the existence of solution to the considered problem. In order to study the question of existence and uniqueness of the weak generalized solution to the problem (1) - - (4), we use the monotonicity method and the Galerkin method. In the second paragraph we present the algorithm of numerical method to find the start control and final observation to the model of potential distribution in a crystalline semiconductor, based on the method of decomposition, method of Ritz, method of penalty and method of Galerkin. The results of computation experiments are given.

\section{Analytical Research of the Problem of Start Control and Final Observation}

Let us consider the functional spaces $\mathfrak{N}=\stackrel{\circ}{W_{4}^{1}}(\Omega), \mathfrak{B}=\stackrel{\circ}{W_{2}^{1}}(\Omega), \mathcal{H}=L_{2}(\Omega)$, defined in the domain $\Omega$. Let $\mathfrak{B}^{*}$ и $\mathfrak{N}^{*}$ be dual spaces to $\mathfrak{B}$ and $\mathfrak{N}$, elative to the scalar product $<\cdot, \cdot>$ in $\mathcal{H}$, respectively. According to the Sobolev theorem there exist dense and continuous embeddings

$$
\mathfrak{N} \hookrightarrow \mathfrak{B} \hookrightarrow \mathcal{H} \hookrightarrow \mathfrak{B}^{*} \hookrightarrow \mathfrak{N}^{*}
$$

Define operators $L, M, N$ :

$$
\begin{gathered}
<L x, y>=\int_{\Omega}(\lambda x y+\nabla x \cdot \nabla y) d s, \quad \forall x, y \in \mathfrak{B}, \\
<M x, y>=a_{1} \int_{\Omega} \nabla x \cdot \nabla y d s, \quad \forall x, y \in \mathfrak{B}, \\
<N(x), y>=a_{2} \int_{\Omega}|\nabla x|^{2} \nabla x \cdot \nabla y d s, \quad \forall x, y \in \mathfrak{N} .
\end{gathered}
$$

Remark 1. In what follows, we will consider $s$-monotonic and $p$-coercive operators. An operator $N$ is called $s$-monotonic if $\left\langle N_{x}^{\prime} y, y>\geq 0 \quad \forall x, y \in \mathfrak{N}\right.$. We also note that if operator $N$ is the $s$-monotonic then operator $N$ is strong monotonic [14]. An operator $N$ is called $p$-coercive [14], if $\exists C_{N}, C^{N}$ и $\exists p \geq 2$ such that $\langle N(x), x\rangle \geq C_{N}\|x\|^{p}$ and $\|N(x)\|_{*} \leq C^{N}\|x\|^{p-1} \quad \forall x \in \mathfrak{N}$. It should be noted, that from $p$-coercive operator follows its strong coercivity.

Let $\left\{\varphi_{k}\right\}$ be a sequence of eigenfunctions of the homogeneous Dirichlet problem for the operator $(-\Delta)$ in the domain $\Omega$, and $\left\{\lambda_{k}\right\}$ be the corresponding sequence of eigenvalues, numbered in non-decreasing order taking into account their multiplicity.

Lemma 1. (i) For all $\lambda \geq-\lambda_{1}$ operator $L \in \mathcal{L}\left(\mathfrak{B}, \mathfrak{B}^{*}\right)$ is self-adjoint, Fredholm and non-negative defined operator.

(ii) For all $a_{1} \in \mathbb{R}_{+}$operator $M \in \mathcal{L}\left(\mathfrak{B}, \mathfrak{B}^{*}\right)$ is s-monotonic u 2-coercive operator. 
(iii) For all $a_{2} \in \mathbb{R}_{+}$operator $N \in C^{\infty}\left(\mathfrak{N}, \mathfrak{N}^{*}\right)$ is s-monotonic u 4-coercive operator.

Proof. Statement $(i)$ is a classical result, since

$$
|<L y, y>|=\left|\int_{\Omega}\left(\lambda y^{2}+\nabla y \cdot \nabla y\right) d s\right| \leq|\lambda| \cdot\|y\|_{\mathcal{H}}^{2}+\|y\|_{\mathfrak{B}}^{2} \leq C\|y\|_{\mathfrak{B}}^{2}, \quad \forall y \in \mathfrak{B} .
$$

The proof of statements $(i i),($ iii $)$ is similar to [9].

By constructing the operators, the initial-boundary value problem (3), (4) for equation (2) is reduced to the Showalter-Sidorov problem

$$
L(x(s, 0)-u(s))=0
$$

for the semilinear Sobolev type equation

$$
L \dot{x}+M x+N(x)=y, \quad \operatorname{ker} L \neq\{0\} .
$$

Let us search for the approximate solutions to the problem $(2)-(4)$ in the form

$$
x^{m}(s, t)=\sum_{i=1}^{m} a_{i}(t) \varphi_{i}(s), \quad m>\operatorname{dim} \operatorname{ker} L,
$$

where the coefficients $a_{i}=a_{i}(t), i=1, \ldots, m$, are determined by the system of equations

$$
\int_{\Omega}\left(\lambda x_{t} \varphi_{i}+\nabla x \cdot \nabla \varphi_{i}\right) d s+\int_{\Omega}\left(a_{1} \nabla x \cdot \nabla \varphi_{i}+a_{2}|\nabla x|^{2} \nabla x \cdot \nabla \varphi_{i}\right) d s=\int_{\Omega} y \varphi_{i} d s
$$

and the conditions

$$
\int_{\Omega}\left[\lambda\left(x_{m}(s, 0)-u(s)\right) \varphi_{i}(s)\right] d s=-\int_{\Omega}\left[\nabla\left(x_{m}(s, 0)-u(s)\right) \cdot \nabla \varphi_{i}(s)\right] d s .
$$

Construct the set

$$
\operatorname{coim} L=\{x \in \mathfrak{B}: \quad\langle x, \varphi>=0 \quad \forall \varphi \in \operatorname{ker} L \backslash\{0\}\}
$$

and consider the space

$$
\mathfrak{X}=\left\{x \mid x \in L_{\infty}(0, T ; \operatorname{coim} L) \cap L_{4}(0, T ; \mathfrak{N})\right\} .
$$

Definition 1. A vector-valued function $x \in \mathfrak{X}$ for $T \in \mathbb{R}_{+} s$ called a weak generalized solution to the Showalter-Sidorov problem (2) - (4), if it satisfies

$$
\begin{gathered}
\int_{0}^{T}\left(\left[L \frac{d x}{d t}, \zeta\right]+[M+N(x), \zeta]\right) d t=0, \quad \zeta \in \mathfrak{N}, \\
{[L(x(0)-u), \zeta]=0 .}
\end{gathered}
$$


Theorem 1. Let $\lambda \geq-\lambda_{1}, a_{1}, a_{2} \in \mathbb{R}_{+}$, then for any $u \in \mathfrak{N}$ and $y \in L_{\frac{4}{3}}\left(0, T ; \mathfrak{N}^{*}\right)$ there exists a unique solution $x \in \mathfrak{X}$ to problem $(2)-(4)$.

As a result of the reduction of the problem (2) - (4) to the problem (6) - (7) this theorem is a consequence [15, Theorem 1]. The Theorem 1 shows the convergence of the Galerkin approximations (8) to the weak generalization solution to problem (2) - (4). We construct the control space $\mathfrak{U}=\mathfrak{N}$ and we choose $\mathfrak{U}_{a d} \subset \mathfrak{U}$ is nonempty, closed, convex set.

Definition 2. A pair $(\tilde{x}(T), \tilde{u}) \in \mathfrak{N} \times \mathfrak{U}_{a d}$ is called a solution to the problem (1) - (4), if

$$
J(\tilde{x}(T), \tilde{u})=\inf _{(x(T), u)} J(x(T), u),
$$

where the pairs $(\tilde{x}, \tilde{u}) \in \mathfrak{X} \times \mathfrak{U}_{a d}$ satisfy to the problem $(2)-(4)$ in the weak generalized case.

Theorem 2. Let $\lambda \geq-\lambda_{1}, a_{1}, a_{2} \in \mathbb{R}_{+}$, then for any $u \in \mathfrak{N} u y \in L_{\frac{4}{3}}\left(0, T ; \mathfrak{N}^{*}\right)$ there exists a unique weak generalized solution $(\tilde{x}(T), \tilde{u})$ to the problem $(1)-(4)$.

Proof. Let $\left\{u_{m}\right\} \subset \mathfrak{U}_{a d}$ is a sequence such that,

$$
\lim _{m \rightarrow \infty} J\left(u_{m}\right)=\inf _{u \in \mathfrak{U}_{a d}} J(u)
$$

then

$$
\left\|u_{m}\right\|_{\mathfrak{N}} \leq \text { const, } \forall m \in \mathbb{N} .
$$

From (12) (move to a subsequence if necessary) we choose a weakly converging sequence $u^{m} \rightarrow \tilde{u}$ in $\mathfrak{N}$. According to the Mazur theorem, the point $\tilde{u} \in \mathfrak{U}_{a d}$. Let $x^{m}=x\left(u^{m}\right)$ be a weakly generalized solution to the problem

$$
\begin{gathered}
L \frac{d}{d t} x^{m}+M x^{m}+N\left(x^{m}\right)=y, \\
L\left(x^{m}(0)-u^{m}\right)=0 .
\end{gathered}
$$

Let norm $|x|^{2}=<L x, x>$ in coim $L$. Multiply the equation (2) by $x^{m}(t)$ and integrate by $(0, t)$. By virtue of 4 -coercivity of $N$ operator for any constant $\varepsilon$, so that $2 C_{N}-\frac{1}{4 \varepsilon^{4}}>0$, we get

$$
\left|x^{m}(t)\right|^{2}+C_{1} \int_{0}^{t}\left\|x^{m}(\tau)\right\|_{\mathfrak{N}}^{4} d \tau \leq \varepsilon^{4} \int_{0}^{t}\|y(\tau)\|_{\mathfrak{N}^{*}}^{\frac{4}{3}} d \tau+|u|^{2}, C_{1}>0 .
$$

In view of the reflexivity of the spaces $L_{4}(0, T ; \mathfrak{N})$ and $L_{\frac{4}{3}}\left(0, T ; \mathfrak{N}^{*}\right)$ there are weak limits:

$$
\begin{gathered}
x^{m} \rightarrow \tilde{x} * \text {-weakly in } L_{\infty}(0, T ; \operatorname{coim} L) ; \\
x^{m} \rightarrow \tilde{x} \text { weakly in } L_{4}(0, T ; \mathfrak{N}) \\
L \frac{d}{d t} x^{m} \rightarrow L \frac{d}{d t} \tilde{x}^{m} \text { weakly in } L_{2}\left(0, T ; \mathfrak{B}^{*}\right) \\
N\left(x^{m}\right) \rightarrow \mu \text { weakly in } L_{\frac{4}{3}}\left(0, T ; \mathfrak{N}^{*}\right) .
\end{gathered}
$$


Since the operator $N$ is 4 -coercive, we obtain

$$
\int_{0}^{T}\left\langle N\left(x^{m}\right), x^{m}\right\rangle d \tau \leq \int_{0}^{T}\left\|N\left(x^{m}\right)\right\|_{\mathfrak{N}^{*}}\left\|x^{m}\right\|_{\mathfrak{N}} d \tau \leq C^{N} \int_{0}^{T}\left\|x^{m}\right\|_{\mathfrak{N}}^{3}\left\|x^{m}\right\|_{\mathfrak{N}} d \tau,
$$

and hence $N\left(x^{m}\right)$ are limited in $L_{\frac{4}{3}}\left(0, T ; \mathfrak{N}^{*}\right)$. Turn to the limit in the state equation (13) and condition (14), we get

$$
L \frac{d \tilde{x}}{d t}+M \tilde{x}+N(\tilde{x})=y, \quad L(\tilde{x}(0)-\tilde{u})=0 .
$$

The proof of the equality $N\left(x^{m}\right)=\mu$ is based on the method of monotonicity in consequence of $s$-monotonicity of operators $M, N[2,12,15]$. Then, $\tilde{x}=\tilde{x}(\tilde{u})$ и $\lim \inf J\left(u_{m}\right) \geq J(\tilde{u})$. Hence, $\tilde{u}$ is start control to the problem $(1)-(4)$.

Some physical processes are described by complex mathematical models and it is not always possible to find analytical solutions. Therefore, the construction numerical algorithms for solving problems is becoming increasingly relevant. Theorem 1 and Theorem 2 establish the existence of a solution, but do not describe the method for finding it. In order to linearize the equation (2) we need to introduce and to find an additional vector-valued function $x(s, t)=v(s, t)$ for a numerical research of the mathematical model of process distribution potential in a semicrystalline semiconductor. Then problem (1)-(4) is equivalent to the following problem

$$
\begin{gathered}
L \dot{x}+M x+N(v)=y, \quad x(u, v)=v, \\
x(0)=u, \\
J_{\theta}(x(T), v(T), u)=\theta \cdot \vartheta\left\|x(T)-x_{f}\right\|_{\mathfrak{N}}^{4}+ \\
+(1-\theta) \cdot \vartheta\left\|v(T)-x_{f}\right\|_{\mathfrak{N}}^{4}+(1-\vartheta)\|u\|_{\mathfrak{N}}^{4} \rightarrow \inf , \quad \theta, \vartheta \in(0,1) .
\end{gathered}
$$

Theorem 3. Let $\lambda \geq-\lambda_{1}, a_{1}, a_{2} \in \mathbb{R}_{+}$, then for any $u \in \mathfrak{N}$ and $y \in L_{\frac{4}{3}}\left(0, T ; \mathfrak{N}^{*}\right)$ there exists a solution to the problem (15), (16).

Proof. The proof of the Theorem follows from Theorem 1, if $\tilde{y}=y-N(v) \in$ $L_{\frac{4}{3}}\left(0, T ; \mathfrak{N}^{*}\right)$.

The penalty method is applicable. Then the problem $(15)-(17)$ is equivalent to the following problem:

$$
\begin{gathered}
L \dot{x}+M x+N(v)=y, \quad x(u, v)=v, \\
x(0)=u, \\
J_{\theta}^{\varepsilon}(x(T), v(T), u)=\theta \cdot \vartheta\left\|x(T)-x_{f}\right\|_{\mathfrak{N}}^{4}+ \\
+(1-\theta) \cdot \vartheta\left\|v(T)-x_{f}\right\|_{\mathfrak{N}}^{4}+(1-\vartheta)\|u\|_{\mathfrak{N}}^{4}+r_{\varepsilon}\|x-v\|_{\mathcal{H}}^{2} \rightarrow \inf , \quad \theta, \vartheta \in(0,1),
\end{gathered}
$$

where the penalty parameter $r_{\varepsilon} \rightarrow+\infty$ if $\varepsilon \rightarrow+0$.

Definition 3. A triple $(\tilde{x}(T), \tilde{v}(T), \tilde{u}) \in \mathfrak{N} \times \mathfrak{N} \times \mathfrak{U}_{a d}$ is called a solution to the problem of start control and final observation (18) - (20), if

$$
J_{\theta}^{\varepsilon}(\tilde{x}(T), \tilde{v}(T), \tilde{u})=\inf _{(x(T), v(T), u)} J_{\theta}^{\varepsilon}(x(T), v(T), u),
$$


where the triple $(x, v, u) \in \mathfrak{X} \times \mathfrak{X} \times \mathfrak{U}_{\text {ad }}$ satisfies (18), (19) in the weak generalized case.

Theorem 4. Let $\lambda \geq-\lambda_{1}, a_{1}, a_{2} \in \mathbb{R}_{+}$, then for any $y \in L_{\frac{4}{3}}(0, T ; \mathfrak{N})$ there exists a solution $\left(x_{\varepsilon}, v_{\varepsilon}, u_{\varepsilon}\right)$ to the problem $(18)-(20)$, moreover $u_{\varepsilon}(T) \rightarrow \tilde{u}(T), x_{\varepsilon}(T) \rightarrow \tilde{x}(T)$ for $\varepsilon \rightarrow+0$.

Proof. Let $\left\{u_{\varepsilon}^{m}\right\} \subset \mathfrak{U}_{a d}$ is sequence, such that

$$
\lim _{m \rightarrow \infty} J_{\theta}^{\varepsilon}\left(u_{\varepsilon}^{m}\right)=\inf _{u \in \mathfrak{U}_{a d}} J(u),
$$

then it follows from $(20)$ that

$$
\left\|u_{\varepsilon}^{m}\right\|_{\mathfrak{N}} \leq \text { const, } \forall m \in \mathbb{N} .
$$

From (21) (move to a subsequence if necessary) we choose a weakly converging sequence $u_{\varepsilon}^{m} \rightarrow \tilde{u}$ в $\mathfrak{N}$. According to the Mazur theorem, the point $\tilde{u} \in \mathfrak{U}_{a d}$.

Let $x_{\varepsilon}^{m}=x\left(v_{\varepsilon}^{m}, u_{\varepsilon}^{m}\right)$ is be a weakly generalized solution to the problem

$$
\begin{gathered}
L \frac{d}{d t} x_{\varepsilon}^{m}+M x_{\varepsilon}^{m}+N\left(v_{\varepsilon}^{m}\right)=y, \quad x_{\varepsilon}^{m}=v_{\varepsilon}^{m}, \\
L\left(x_{\varepsilon}^{m}(0)-u_{\varepsilon}^{m}\right)=0 .
\end{gathered}
$$

Then, by virtue of reasoning similar to the evidence of Theorem 2 follows that

$$
N\left(v_{\varepsilon}^{m}\right) \in L_{\frac{4}{3}}\left(0, T ; \mathfrak{N}^{*}\right), M x_{\varepsilon}^{m} \in L_{2}\left(0, T ; \mathfrak{B}^{*}\right)
$$

and going to the limit in (22) get

$$
L \frac{d \tilde{x}}{d t}+M \tilde{x}+\mu=y, \quad L(\tilde{x}(0)-\tilde{u})=0
$$

From the fact that the functional (20) by construction is continuous, limited and coercive, it follows that

$$
\left\|\sqrt{r_{\varepsilon}}\left(x_{\varepsilon}^{m}-v_{\varepsilon}^{m}\right)\right\|_{L_{2}(0, T ; \mathcal{H})} \leq \text { const, } \forall m \in \mathbb{N} .
$$

Since the penalty parameter $r_{\varepsilon} \rightarrow+\infty$ if $\varepsilon \rightarrow+0$, then from (23) follows

$$
x_{\varepsilon}^{m}-v_{\varepsilon}^{m} \rightarrow 0 \text { в } L_{2}(0, T ; \mathcal{H})
$$

By virtue of (24) and the second equation (22), we obtain

$$
\begin{aligned}
& x_{\varepsilon}^{m} \rightarrow \tilde{x} \text { в } L_{2}(0, T ; \mathcal{H}), \\
& v_{\varepsilon}^{m} \rightarrow \tilde{x} \text { в } L_{2}(0, T ; \mathcal{H}) .
\end{aligned}
$$

From (26) we obtain that $\mu=N \tilde{(v)}$. Hence $\hat{x}=\hat{x}(\hat{v}, \hat{u})$ and $\lim \inf J\left(u_{m}, v_{m}\right) \geq J(\hat{u}, \hat{v})$. So $(\hat{u}(T), \hat{v}(T), \tilde{u})$ there is a solution to the problem $(18)-(20)$. 


\section{Algorithm of the Numerical Method to Find the Start Control and Final Observation}

Based on the theoretical results obtained in the previous paragraphs, we develop an algorithm to find the approximate solution to the problem of start control and final observation for the mathematical model of control of potential distribution in a crystalline semiconductor on the basis of the modified decomposition method, method of Galerkin and method of Ritz. Let $\sigma$ be a spectrum of the operator $(-\Delta)$ with the homogeneous Dirichlet condition, and $\left\{\lambda_{i}\right\}$ be a set of the eigenvalues numbered in non-decreasing order and $\left\{\varphi_{i}\right\}$ be a family of the corresponding eigenfunctions, which are orthonormalized relatively to the scalar product $\langle\cdot, \cdot\rangle$ in $L_{2}(\Omega)$. Next, we will seek an approximate solution to the control problem (1) - (4) using the Galerkin method, method of decomposition and method of penalty described in [13]. Applying the penalty method, we proceed to consider the control problem (18) - (20), where the proximity of the approximate solutions $\tilde{x}$ and $\tilde{v}$ is achieved by introducing a new functional in the form (20), where the penalty parameter is $r_{\varepsilon} \rightarrow+\infty$ at $\varepsilon \rightarrow 0+$. Using the method of Galerkin, an approximate solution of $\tilde{x}, \tilde{v}, \tilde{u}$ of the control problem (18) - (20) we'll be looking in the form

$$
\tilde{x}(s, t)=\sum_{i=1}^{m} a_{i}(t) \varphi_{i}(s), \quad \tilde{u}=\sum_{i=1}^{m} u_{i} \varphi_{i}(s), \quad \tilde{v}(s, t)=\sum_{i=1}^{m} v_{i}(t) \varphi_{i}(s),
$$

where $m \in \mathbb{N}$, such that $m>l$, where $l=\operatorname{dim} \operatorname{ker} L$. It is in order to take into account the effects of the degenerate equation.

To find the unknown coefficients, we create system of differential equation

$$
<(\lambda-\Delta) x_{t}, \varphi_{i}>-a_{1}<\Delta x, \varphi_{i}>-a_{2}<\operatorname{div}\left(|\nabla v|^{2} \nabla v\right), \varphi_{i}>=<y, \varphi_{i}>
$$

with the Showalter-Sidorov conditions

$$
<(\lambda-\Delta)(x(s, 0)-u(s)), \varphi_{i}>=0 .
$$

Solve the problem $(27),(28)$ relatively the unknown $a_{i}(t)$, Note that depending on parameter $\lambda$, equations in the system can be either differential or algebraic. Consider these cases in more details:

- If $\lambda \notin \sigma$, then all equations of the system (27) is ordinary differential equations of the first order. In order to solve this system relatively $a_{i}(t), i=1, \ldots, m$, we find $m$ initial conditions $a_{i}(0)=u_{i}, \quad i=1, . ., m$, from the initial conditions (28). Further, we solve the obtained system of the linear differential equations of the first order with the initial conditions, and express unknown coefficients $a_{i}(t)$ of the approximate solution $\tilde{x}(s, t)$ by $v_{i}(t), u_{i}, i=1, . ., m$.

- If $\lambda \in \sigma$, then the first equation is algebraic, and the rest ones are differential. Separately, consider the system of differential equations having first order and the algebraic equation. Using the Showalter - Sidorov conditions, we find $(m-1)$ initial conditions. Solve the system of the algebraic and differential equations, and express the unknown coefficients $a_{i}(t), i=2, . ., m$ of the approximate solution $\tilde{x}(s, t)$ by $v_{i}(t)$, and $u_{i}, i=1, . ., m$. From the algebraic equation we find $a_{1}(t)$ and $u_{1}=a_{1}(0)$. Turn to search for the minimum of functional. Substitute the obtained decompositions in the functional. 
Based on method of Ritz, we will search for unknowns $v_{i}(t), i=1, . ., m$, in the form

$$
v_{i}(t, N)=\sum_{i=1}^{N} b_{n} t^{n}
$$

such that $v_{i}(0, N)=x_{i}(0)=u_{i}, \quad i=1, . ., m$. Let's move on to finding minimum functional, we substitute the obtained decompositions into the functional. We will be take the coefficients $b_{n}$ so that the functions $v_{i}(t, N)$ and $u_{i}(N)$ deliver a minimum functional (20). Thus, the problem reduces to finding the extremum of the function of several variables.

Example. The problem is to find an approximate solution to the problem of start control and final observation of the problem (1) - (4) for $\lambda=-1 ; a_{1}=5 ; a_{2}=4 ; \Omega=$ $(0, \pi) ; T=0,4 ; \theta=\frac{21}{55}, \quad \beta=\frac{999}{1000} ; \varepsilon=\frac{1}{200} ; m=2 ; N=3 ; x_{f}=\frac{\sqrt{2}}{3 \sqrt{\pi}} \sin (s) ; y=0$.

On the basis of the developed numerical method to find the start control and final observation, we turn to an equivalent problem of the start control and final observation:

$$
\begin{gathered}
J(x(T), v(T), u)=\frac{21}{55} \cdot \frac{999}{1000} \int_{0}^{\pi}\left|x(s, T)-\frac{\sqrt{2}}{3 \sqrt{\pi}} \sin s\right|^{4} d s+ \\
+\left(1-\frac{21}{55}\right) \cdot \frac{999}{1000} \int_{0}^{\pi}\left|v(s, T)-\frac{\sqrt{2}}{3 \sqrt{\pi}} \sin s\right|^{4} d s+ \\
+\left(1-\frac{999}{1000}\right) \int_{0}^{\pi}|u(s)|^{2} d s+200 \int_{0}^{\pi} \int_{0}^{T}|x(s, t)-v(s, t)|^{2} d s d t \rightarrow \inf
\end{gathered}
$$

solutions by the solutions to the problem (2) - (4). Consider the Sturm-Liouville problem

$$
-X^{\prime \prime}(x)=\lambda X(x), \quad X(0)=X(\pi)=0 .
$$

The eigenfunctions and eigenvalues of the problem (30) have the form:

$$
\varphi_{i}(s)=\sqrt{\frac{2}{\pi}} \sin (i s), \lambda_{i}=i^{2}, i=1,2 .
$$

The results of the program "Numerical research of the mathematical model of control potential distribution in a crystalline semiconductor" calculations are control coefficients such that the value of the functional $J=0,00000285$. Graphs of approximate solution are shown in Fig. 1. In order to compare the obtained functions $\tilde{x}(s, t), \tilde{v}(s, t)$ and the required state $x_{f}(s)$ we construct the graph of these functions at the moment $t=0,4$ (see Fig. 2).

Moreover, the initial function $\tilde{u}(s)$ has the form:

$$
\tilde{u}(s)=\sqrt{\frac{2}{\pi}}(0,349395424933796 \sin s-0,840135401320449 \sin 2 s) .
$$

The difference between the required functions $\tilde{x}(s, t)$ and $\tilde{v}(s, t)$ is small:

$$
\Delta=\left(\int_{0}^{T}\left(\int_{0}^{\pi}|\tilde{x}(s, t)-\tilde{v}(s, t)|^{4} d s\right) d t\right)^{\frac{1}{4}}=0,0000012365046 .
$$




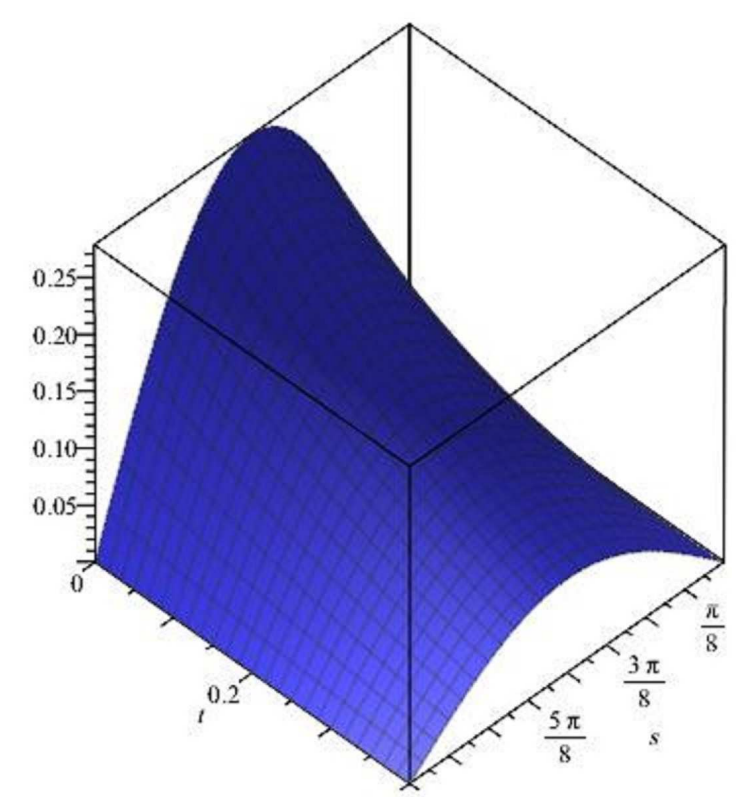

a) function $\tilde{x}(s, t)$

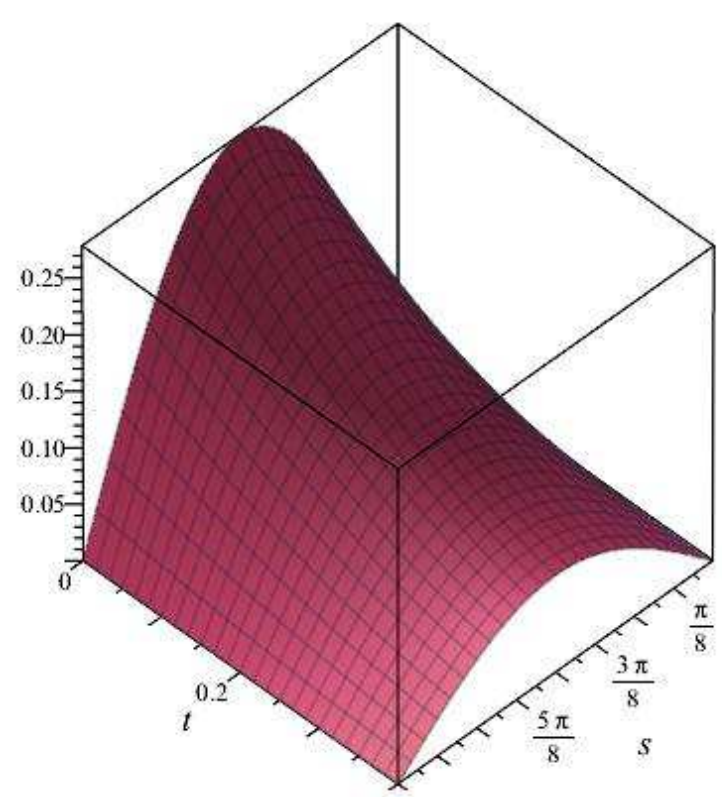

b) function $\tilde{v}(s, t)$

Fig. 1. The approximate solution $\tilde{x}(s, t), \tilde{v}(s, t)$ to the problem $(2)-(4)$

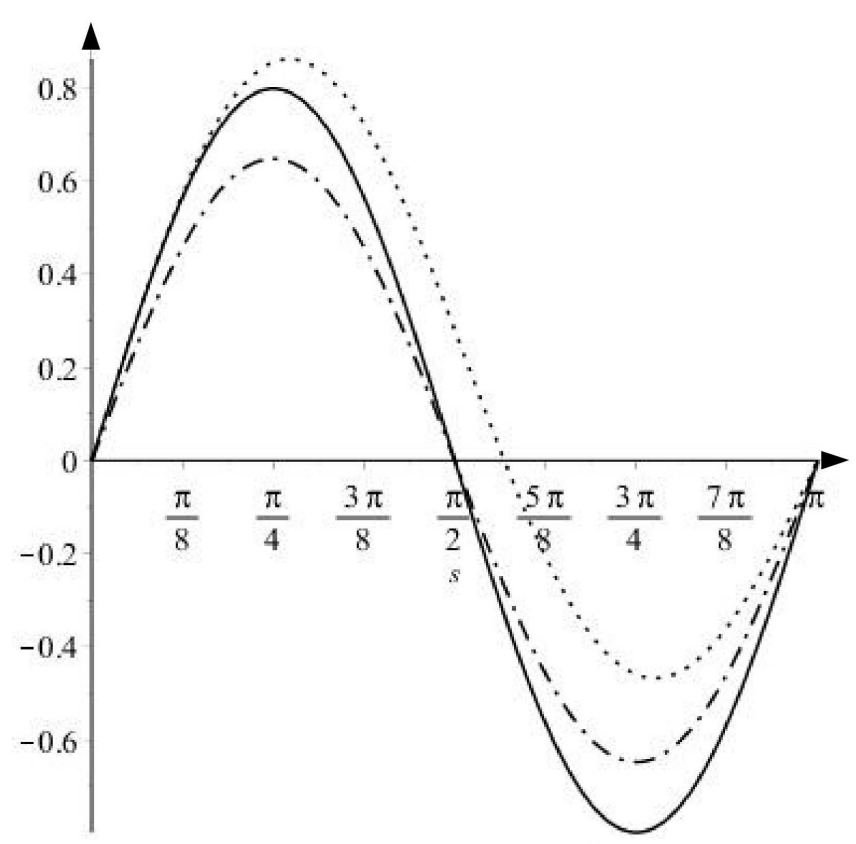

Fig. 2. Functions $\tilde{x}(s ; 0,4), \tilde{v}(s ; 0,4), x_{f}(s), s \in(0, \pi)$

To evaluate the obtained solution of the start control problem and final observation (1) - (4) we find an approximate solution to the problem of Showalter-Sidorov (2), (3) for 
the original equation (1) with the initial functions $\tilde{u}(s)$. As a result of the program, we have a numerical solution $\hat{x}(s, t)$ (see Table 1 and Fig. 3).

Table 1

Coefficients solution to problem $(1)-(4)$

\begin{tabular}{|c||c|c|}
\hline$t$ & $a_{1}(t)$ & $a_{2}(t)$ \\
\hline 0 & 0,348805813 & $-0,4215741947$ \\
0,1 & 0,268597874 & $-0,2762745402$ \\
0,2 & 0,207780867 & $-0,1827157108$ \\
0,3 & 0,161167621 & $-0,12149255395$ \\
0,4 & 0,125212306 & $-0,81043204980$ \\
\hline
\end{tabular}

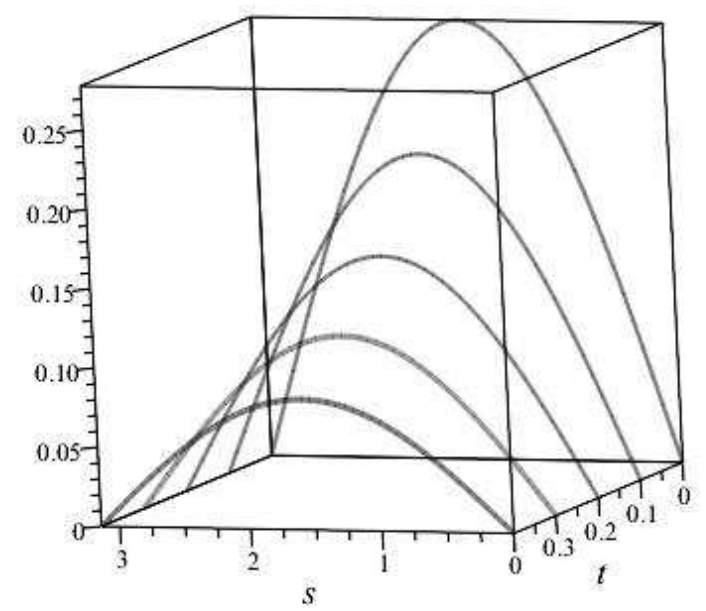

a)

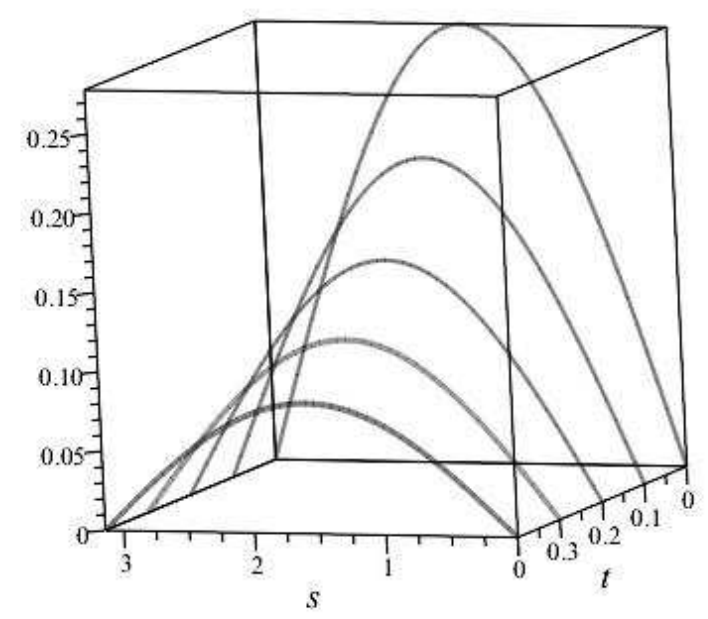

b)

Fig. 3. a) An approximate solution $\tilde{x}(s, t)$ to the problem $(1)-(4)$ at different instants of time $t ; \mathrm{b})$ an approximate solution $\hat{x}(s, t)$ to the problem $(1)-(4)$ at different instants of time $t$

To evaluate (see Table 2) the obtained approximate solution $\tilde{x}(s, t)$, found using the method of decomposition and numerical solution of $\hat{x}(s, t)$ the initial problem for a given $\tilde{u}(s)$ were found:

$$
\Delta_{t_{i}}=\left(\int_{0}^{\pi}\left|\tilde{x}\left(s, t_{i}\right)-\hat{x}\left(s, t_{i}\right)\right|^{4} d s\right)^{\frac{1}{4}} .
$$

So we can conclude that, given the parameters found such an initial initial state of the system $u(s)$, at which the potential distribution $x(s, t)$ in the crystalline semiconductor after a predetermined time, close to the desired value of $x_{f}(s)$. 


\section{Table 2}

Value $\Delta_{t_{i}}$ at various points in time

\begin{tabular}{|c|c|c|c|}
\hline$\Delta_{0,1}$ & $\Delta_{0,2}$ & $\Delta_{0,3}$ & $\Delta_{0,4}$ \\
\hline 0,199062 & 0,030231 & 0,034509 & 0,035085 \\
\hline
\end{tabular}

The work was supported by Act 211 Government of the Russian Federation, contract No. 02.A03.21.0011.

\section{References}

1. Korpusov M. O., Sveshnikov A. G. Three-Dimensional Nonlinear Evolution Equations of Pseudoparabolic Type in Problems of Mathematical Physics. V. II. Computational Mathematics and Mathematical Physics, 2003, vol. 43, no. 12, pp. 1942-1948. (in Russian)

2. Al'shin A. B., Korpusov M. O., Sveshnikov A. G. Blow-Up in Nonlinear Sobolev Type Equations. Berlin, Walter de Gruyter, 2011. DOI: 10.1134/S001226610603013X

3. Keller A. V., Shestakov A. L., Sviridyuk G. A., Khudyakov Yu. V. The Numerical Algorithms for the Measurement of the Deterministic and Stochastic Signals. Semigroups of Operators Theory and Applications, 2015, vol. 113, pp. 183-195. DOI: $10.1007 / 978-3-319-12145-1 \_11$

4. Zamyshlyaeva A. A., Lut A. V. Numerical Investigation of the Boussinesq-Love Mathematical Models on Geometrical Graphs. Bulletin of the South Ural State University. Series: Mathematical Modelling, Programming and Computer Software, 2017, vol. 10, no. 2, pp. 137-143. DOI: 10.14529/mmp170211

5. Bogatyreva E. A. The Start Control and Final Observation Problem for a Quasilinear Sobolev Type Equation. Bulletin of the South Ural State University. Series: Mathematics. Mechanics. Physics, 2015, vol. 7, no. 4, pp. 5-10. (in Russian) DOI: $10.14529 / \mathrm{mmph} 150401$

6. Zamyshlyaeva A.A., Tsyplenkova O. N. Optimal Control of Solutions of the ShowalterSidorov-Dirichlet Problem for the Boussinesq-Love Equation. Differential Equations, 2013, vol. 49, no. 11, pp. 1356-1365. DOI: 10.1134/S0012266113110049

7. Manakova N. A., Vasiuchkova K. V. Numerical Investigation for the Start Control and Final Observation Problem in Model of an I-Beam Deformation. Journal of Computational and Engineering Mathematics, 2017, vol. 4, no. 2, pp. 26-40. DOI: 10.14529 jcem170203

8. Fursikov A. V. Optimal Control of Distributed Systems. Theory and Applications. Novosibirsk, Nauchnaya kniga, 1999. (in Russian)

9. Manakova N. A., Vasiuchkova K. V. Research of One Mathematical Model of the Distribution of Potentials in a Crystalline Semiconductor. Bulletin of the South Ural State University. Series: Mathematical Modelling, Programming and Computer Software, 2019, vol. 12, no. 2, pp. 150-157. DOI: 10.14529/mmp190213 
10. Manakova N. A., Sviridyuk G. A. Nonclassical Equations of Mathematical Physics. Phase Spaces of Semilinear Sobolev Type Equations. Bulletin of the South Ural State University. Series Mathematics. Mechanics. Physics, 2016, vol. 8, no. 3, pp. 31-51. (in Russian)

11. Sviridyuk G. A., Karamova A. F. On the Phase Space Fold of a Nonclassical Equation. Differential Equations, 2005, vol. 41, no. 10, pp. 1476-1481. DOI: 10.1007/s10625-0050300-5

12. Lions J.-L. Controle optimal de systemes gouvernes par des equations aux daerivaes partielles. Paris, Dunod, 1968. (in French)

13. Manakova N. A. Method of Decomposition in the Optimal Control Problem for Semilinear Sobolev Type Models. Bulletin of the South Ural State University. Series: Mathematical Modelling, Programming and Computer Software, 2015, vol. 8, no. 2, pp. 133-137. (in Russian) DOI: 10.14529/mmp150212

14. Sviridyuk G. A. A Problem for the Generalized Boussinesq Filtration Equations. Soviet Mathematics, 1989, vol. 33, no 2, pp. 62-73.

15. Manakova N. A., An Optimal Control to Solutions of the Showalter-Sidorov Problem for the Hoff Model on the Geometrical Graph. Journal of Computational and Engineering Mathematics, 2014, vol. 1, no. 1, pp. 26-33.

Ksenia V. Vasiuchkova, PhD Student, Department of Mathematical Physics Equations, South Ural State University (Chelyabinsk, Russian Federation), vasiuchkovakv@susu.ru.

\title{
ЧИСЛЕННОЕ ИССЛЕДОВАНИЕ ДЛЯ ЗАДАЧИ СТАРТОВОГО УПРАВЛЕНИЯ И ФИНАЛЬНОГО НАБЛЮДЕНИЯ В МОДЕЛИ РАСПРЕДЕЛЕНИЯ ПОТЕНЦИАЛОВ В КРИСТАЛЛИЧЕСКОМ ПОЛУПРОВОДНИКЕ
}

\author{
К. В. Васючкова
}

\begin{abstract}
Статья посвящена численному исследованию математической модели управления распределением потенциалов в кристаллическом полупроводнике. Данная модель основана на задаче стартового управления и финального наблюдения слабыми обобщенными решениями математической модели распределения потенциалов в кристаллическом полупроводнике. Данная модель относится к классу математических моделей, основанных на полулинейных уравнениях соболевского типа с $p$-коэрцитивным и $s$ монотонным операторами.
\end{abstract}




\begin{abstract}
Нами показано существование и единственность слабого обобщенного решения исследуемой модели с начальным условием Шоуолтера-Сидорова и найдены достаточные условия существования решения задачи стартового управления и финального наблюдения. Построен алгоритм численного метода нахождения приближенного решениями задачи стартового управления и финального наблюдения исследуемой задачи на основе методов декомпозиции и метода Галеркина. Приводятся вычислительные эксперименты.

Ключевые слова: уравнения соболевского типа; задача стартового управления и финального наблюдения; математическое моделирование; проекиионный метод Галеркина; метод декомпозиции.
\end{abstract}

\title{
Литература
}

1. Korpusov, M. O. Three-Dimensional Nonlinear Evolution Equations of Pseudoparabolic Type in Problems of Mathematical Physics. V. II. / M. O. Korpusov, A. G. Sveshnikov // Computational Mathematics and Mathematical Physics. - 2003. T. 43, № 12. - P. 1942-1948.

2. Al'shin, A. B. Blow-Up in Nonlinear Sobolev Type Equations / A. B. Al'shin, M. O. Korpusov, A. G. Sveshnikov. - Berlin: Walter de Gruyter, 2011.

3. Keller, A. V. The Numerical Algorithms for the Measurement of the Deterministic and Stochastic Signals / A. V. Keller, A. L. Shestakov, G. A. Sviridyuk, Yu. V. Khudyakov // Springer Proceedings in Mathematics and Statistics. - 2015. T. 113. - P. 183-195.

4. Zamyshlyaeva, A. A. Numerical Investigation of the Boussinesq - Love Mathematical Models on Geometrical Graphs / A. A Zamyshlyaeva, A. V. Lut // Вестник ЮУрГУ. Серия: Математическое моделирование и программирование. - 2017. - Т. 10, № 2. - P. 137-143.

5. Богатырева, Е. А. Задача стартового управления и финального наблюдения для одного квазилинейного уравнения соболевского типа / Е. А. Богатырева // Вестник ЮУрГУ. Серия: Математика. Механика. Физика. - 2015. -№ 4. - С. 5-10.

6. Zamyshlyaeva, A. A. Optimal Control of Solutions of the Showalter-SidorovDirichlet Problem for the Boussinesq-Love Equation / A. A. Zamyshlyaeva, O. N. Tsyplenkova // Differential Equations. - 2013. - T. 49, № 11. - P. 1356-1365.

7. Manakova, N. A. Numerical Investigation for the Start Control and Final Observation in Model of I-Beam Deformation / N. A. Manakova, K. V. Vasiuchkova // Journal of Computational and Engineering Mathematics. - 2017. - T. 4, № 2. - P. 26-40.

8. Фурсиков, А. В. Оптимальное управление распределенными системами. Теория и приложения / А. В. Фурсиков. - Новосибирск: Научная книга, 1999.

9. Манакова, Н. А. Исследование одной математической модели распределения потенциалов в кристаллическом полупроводнике / Н. А. Манакова, К. В. Васючкова // Вестник ЮУрГУ. Серия: Математическое моделирование и программирование. - 2019. - Т. 12, № 2. - С. 150-157.

10. Манакова, Н. А. Неклассические уравнения математической физики. Фазовые пространства полулинейных уравнений соболевского типа / Н. А. Манакова, Г. А. Свиридюк // Вестник ЮУрГУ. Серия: Математика. Механика. Физика. 2016. - T. 8, № 3. - C. 31-51. 
11. Свиридюк, Г. А. О складке фазового пространства одного неклассического уравнения / Г. А. Свиридюк, А.Ф. Карамова // Дифференциальные уравнения. 2005. - T. 41, № 10. - C. 1400-1405.

12. Лионс, Ж.-Л. Управление сингулярными распределенными системами / Ж.-Л. Лионс. - М.: Наука, 1987.

13. Манакова, Н. А. Метод декомпозиции в задаче оптимального управления для полулинейных моделей соболевского типа / Н. А. Манакова // Вестник ЮУрГУ. Серия: Математическое моделирование и программирование. - 2015. - Т. 8, № 2. C. $133-137$.

14. Свиридюк, Г. А. Одна задача для обобщенного фильтрационного уравнения Буссинеска / Г. А. Свиридюк / / Известия вузов. Математика. - 1989. - № 2. - С. 55-61.

15. Manakova, N. A. An Optimal Control to Solutions of the Showalter-Sidorov Problem for the Hoff Model of the Geometrical Graph / N. A. Manakova, G. A. Sviridyuk // Journal of Computational and Engineering Mathematics. - 2014. - T. 1, № 1. C. 26-33.

Васючкова Ксения Владимировна, аспирант, кафедра уравнений математической физики, Южно-Уральский государственный университет (г. Челябинск, Российская Федераиия), vasiuchkovakv@susu.ru.

Поступила в редакиию 17 августа 2019 г. 